\section{Efeito de uma sessão de hemodiálise sobre o estresse oxidativo sistêmico de pacientes renais crônicos terminais}

\author{
Effect of a hemodialysis session on oxidative stress of chronic kidney \\ disease patients
}

\begin{abstract}
Autores
Patrícia Dall'Agnol

Bianchi $^{1}$

Jaqueline Barp ${ }^{2}$

Fernando Saldanha

Thomé ${ }^{3}$

Adriane Belló-Klein ${ }^{4}$

'Universidade de Cruz Alta (UNICRUZ)

${ }^{2}$ Universidade Federal

do Rio Grande do Sul

${ }^{3}$ Departamento de

Medicina Interna da

Universidade Federal do

Rio Grande do Sul

${ }^{4}$ Departamento de

Fisiologia, Universidade

Federal do Rio Grande

do Sul
\end{abstract}

Data de submissão: 02/03/2009 Data de aprovação: 03/07/2009

Correspondência para:

Patrícia Dall'Agnol Bianchi

Rua Venâncio Aires,

1.769/901

Cruz Alta - RS

CEP: $98005-020$

Tel: (55) 3322-3799/

(55) 3321-1606/ 8403-3762

Os autores declararam ter recebido suporte financeiro do CNPq, CAPES, FIPE/ HCPA.

\section{Resumo}

Objetivo: Avaliar a repercussão de uma sessão de hemodiálise (HD) sobre o estresse oxidativo sistêmico de pacientes renais crônicos. Métodos e Resultados: Foram avaliados 17 pacientes (10 mulheres) com média de idade de 39,9 $\pm 13,5$ anos em tratamento hemodialítico na Unidade de Nefrologia do HCPA, e o grupo controle formado por 18 indivíduos saudáveis (4 mulheres), com média de idade de 34,8 $\pm 10,1$ anos. O sangue dos doentes renais foi coletado antes e após a sessão de HD. As médias foram analisadas pelo teste $t$ de Student $(\mathrm{p}<0,05)$. Nos eritrócitos, avaliou-se a atividade das enzimas antioxidantes superóxido dismutase (SOD) e catalase (CAT). No plasma, avaliou-se o sistema antioxidante não enzimático por meio da mensuração da capacidade antioxidante total (TRAP). Não houve diferença significativa entre os valores de SOD e CAT antes e após HD. Comparando com o grupo controle, observou-se redução significativa na atividade dessas enzimas. O TRAP apresentou redução significativa após sessão de HD. $\mathrm{O}$ dano oxidativo a lipídios de membrana foi avaliado por quimiluminescência (QL), enquanto o dano às proteínas, pelo método das carbonilas. Não houve diferença significativa entre os valores de QL e Carbonilas após HD. Porém, quando comparados com o grupo controle, observou-se diferença significativa indicando maior dano aos lipídios de membrana e às proteínas nos doentes renais. Conclusões: Pacientes renais crônicos tratados com HD apresentam redução na atividade das enzimas antioxidantes SOD e CAT, bem como dano oxidativo aumentado quando comparado com indivíduos saudáveis e uma sessão de HD não modifica esses níveis.

Palavras-chave: estresse oxidativo, hemodiálise, doença renal crônica.

[J Bras Nefrol 2009;31(3):175-182] OElsevier Editora Ltda.

\section{Abstract}

Objective: To assess the effect of a hemodialysis (HD) session on systemic oxidative stress of chronic renal patients. Methods and Results: The study comprised 17 patients (10 women and 7 men with mean age of $39.9 \pm 13.5$ years) undergoing hemodialytic treatment at the Unit of Nephrology of Hospital de Clínicas de Porto Alegre, and a control group formed by 18 healthy individuals (4 women and 14 men with mean age of $34.8 \pm 10.1$ years). Renal patients had blood samples withdrawn before and after HD session. Means were analyzed by Student $t$ test $(\mathrm{p}<0.05)$. In red blood cells, the activity of the antioxidant enzymes superoxide dismutase (SOD) and catalase (CAT) was assessed. In plasma, the non-enzymatic antioxidant system was assessed by measuring the total reactive antioxidant potential (TRAP). No significant differences were observed between the values of SOD and CAT before and after HD. Comparison with the control group showed a significant reduction in the activity of those enzymes. After HD session, a significant reduction in TRAP was observed. Oxidative damage to membrane lipids was assessed through chemiluminescence $(\mathrm{CL})$, and the damage to proteins through carbonyl assay. No significant difference was observed in the values of CL and carbonyls after HD. However, when compared with the control group, a significant difference was observed, indicating a greater damage to membrane lipids and proteins in renal patients. Conclusions: Chronic renal patients on $\mathrm{HD}$ treatment show a reduction in the activity of antioxidant enzymes SOD and CAT, in addition to an increase in oxidative damage, when compared with healthy individuals. One $\mathrm{HD}$ session does not change those levels.

Keywords: oxidative stress, hemodialysis, chronic kidney disease. 


\section{INTRODUÇÃO}

A doença renal crônica é acompanhada por um complexo de comorbidades. Algumas manifestações, como envelhecimento acelerado, catarata, aterosclerose, diminuição das células vermelhas do sangue, aumento da hemólise e disfunção plaquetária, estão presentes nestes indivíduos, e tais patologias podem estar associadas à hiperprodução de radicais livres. ${ }^{1}$

As doenças ateroscleróticas cardiovasculares são preconizadas como a maior causa de morbidade e mortalidade em pacientes urêmicos. $\mathrm{O}$ desenvolvimento de aterosclerose acelerada envolve múltiplos fatores de risco. Alguns são similares aos reportados para a população em geral, como idade, tabagismo, diabetes mellitus, hipertensão arterial sistêmica e dislipidemia. Outros mais específicos estão associados às consequências da perda de néfrons e levam a distúrbios metabólicos como hiperfibrinogenia, hiperhomocisteinemia e estresse oxidativo. ${ }^{2}$

Alguns autores sugerem que a uremia é um estado pró-oxidante, com aumento nos níveis de lipoperoxidação e diminuição da atividade antioxidante. ${ }^{1,3,4,5}$ Porém, não está clara a natureza desse estresse oxidativo e se o mesmo é exacerbado pela diálise. ${ }^{3,5}$ A lipoperoxidação tem sido associada à patogênese de doenças comumente encontradas em indivíduos que realizam hemodiálise (HD). Níveis plasmáticos aumentados de substâncias reativas ao ácido tiobarbitúrico (TBARS), um marcador da peroxidação lipídica, têm sido relatados em pacientes renais crônicos que realizam tratamento dialítico. ${ }^{1,3,6}$ Além disso, outras complicações, como hemorragia e hipotensão durante o curso da doença e do tratamento hemodialítico, estão possivelmente associadas a um radical livre em especial, o óxido nítrico. O óxido nítrico pode também ter efeitos deletérios devido à sua interação com o radical superóxido, formando o peroxinitrito, altamente reativo.

Além de os marcadores de estresse oxidativo estarem aumentados nos pacientes renais crônicos, neles os mecanismos de defesa podem estar suprimidos. Uma redução do sistema enzimático de defesa, bem como do sistema não enzimático, favoreceria o ataque das espécies ativas de oxigênio $(\mathrm{EAO})$ às células com consequente dano celular. ${ }^{1,6,7}$

Este estudo teve como objetivo avaliar os efeitos de uma sessão de hemodiálise sobre o estresse oxidativo sistêmicos de pacientes renais crônicos em programa de HD.

\section{Métodos}

Foram avaliados 17 pacientes, 10 do sexo feminino com média de idade de $39,9 \pm 13,5$ anos, em tratamento hemodialítico na Unidade de Nefrologia do Hospital de Clínicas de Porto Alegre. Os pacientes avaliados realizavam três sessões semanais de HD com duração média de 4,2 $\pm 0,3$ horas. A média de tratamento com HD nos pacientes foi de 45,2 \pm 40 meses. Utilizaram-se como critérios de exclusão pacientes com doenças hepáticas, processos inflamatórios crônicos conhecidos, doença cardíaca conhecida, tabagismo e alcoolismo. Como não existem valores previstos de normalidade para as variáveis do estresse oxidativo, optou-se por analisar um grupo de pessoas sem nenhum tipo de patologia conhecida e não fumantes. Para tanto, avaliou-se o sangue de 18 doadores, quatro mulheres, com média de idade de $34,8 \pm 10,1$ anos, do Banco de Sangue do Hospital de Clínicas de Porto Alegre. Esse grupo de indivíduos foi denominado grupo controle.

O estudo foi avaliado e aprovado em seus aspectos éticos e metodológicos pela Comissão Científica e pela Comissão de Pesquisa e Ética em Saúde do HCPA. Antes das avaliações, todos os pacientes assinaram termo de consentimento livre e esclarecido.

\section{Coleta sanguínea}

A coleta de sangue nos pacientes em HD foi realizada em dois momentos distintos: no início da sessão de HD (pré-HD), quando os pacientes eram ligados às máquinas dialisadoras, e ao término da sessão (pósHD). As coletas foram realizadas na porção arterial da fístula arteriovenosa. O sangue foi armazenado em um tubo de coleta a vácuo contendo anticoagulante heparina $(10 \mathrm{~mL})$. Para mensuração de ácido úrico nas amostras de plasma, utilizou-se um kit Ácido Úrico - Liquiform, do laboratório LABTEST Diagnóstica. A avaliação do estresse oxidativo foi realizada no Laboratório de Fisiologia Cardiovascular do Departamento de Fisiologia do Instituto de Ciências Básicas da Saúde (ICBS) da Universidade Federal do Rio Grande do Sul. A coleta de sangue no grupo controle, realizada para análise do estresse oxidativo, foi efetuada ao final da doação.

\section{Preparo do sangue para avaliação do estresse OXIDATIVO}

O preparo do sangue para avaliação do estresse oxidativo foi impreterivelmente realizado no dia da coleta. Após a coleta, o sangue armazenado em tubo com anticoagulante heparina era centrifugado por 20 minutos a $3000 \mathrm{rpm}$ em centrífuga refrigerada (Sorvall RC 5B - Rotor SM 24), o plasma era retirado, aliquotado em tubos tipo Eppendorff de 2,0 mL 
e armazenado à temperatura de $800^{\circ} \mathrm{C}$ negativos. Os eritrócitos eram lavados com soro fisiológico $(\mathrm{NaCl}$ $0,9 \%)$ por três vezes. Após a lavagem dos eritrócitos, parte $(75 \mu \mathrm{L})$ era diluída em $500 \mu \mathrm{L}$ de soro fisiológico para medida de lipoperoxidação por quimiluminescência e concentração de hemoglobina. Essas medidas eram realizadas no dia da coleta. Os eritrócitos restantes eram aliquotados e armazenados em freezer a $-80{ }^{\circ} \mathrm{C}$. Estes eritrócitos eram armazenados em solução de ácido acético $1 \mathrm{mM}$ e sulfato de magnésio $4 \mathrm{mM}$. Estas amostras eram utilizadas para análise de proteínas e atividade das enzimas antioxidantes, catalase (CAT) e superóxido dismutase (SOD). O plasma foi utilizado para avaliação da oxidação de proteínas pelo método das carbonilas e para determinação de nitratos e nitritos.

\section{DOSAGEM DE HEMOGLOBINA}

A hemoglobina foi dosada nas amostras de sangue preparadas com soro fisiológico, utilizadas para mensuração da lipoperoxidação. Para análise, utilizou-se uma mistura de cianetos, obtendo-se, assim, o reagente de Drabkin, que interage com a hemoglobina, formando cianometa-hemoglobina, medida em espectrofotômetro. $\mathrm{O}$ espectrofotômetro utilizado neste trabalho foi da marca Varian, modelo Cary. Para as dosagens, colocou-se em um tubo de ensaio a quantidade de $5 \mathrm{~mL}$ da solução de Drabkin e $20 \mu \mathrm{L}$ de amostra, deixou-se reagir por cinco minutos e a absorbância foi lida no espectrofotômetro a um comprimento de onda de $546 \mathrm{~nm}$. Os resultados foram expressos em miligramas por mililitros (mg.ml-1).

\section{LIPOPEROXIDAÇÃO (LPO) - QUIMILUMINESCÊNCIA (QL) INICIADA POR T-BOOH}

A QL foi medida em um contador beta (LKB Rack Beta Liquid Scintilation Spectrometer-1215; LKB Produkter AB, Bromma, Sweden) com circuito de coincidência desconectado e utilizando o canal de trítio. As determinações foram realizadas em sala escu$\mathrm{ra}$, em frascos de vidro mantidos na penumbra para evitar a fosforescência ativada pela luz fluorescente. O meio de reação no qual foi realizado o ensaio consistiu em $4 \mathrm{~mL}$ de uma solução reguladora de $\mathrm{KCl} 140 \mathrm{mM}$, fosfatos $20 \mathrm{mM}, \mathrm{pH} 7,4$, na qual foi adicionado 10 $\mu \mathrm{L}$ de eritrócitos diluídos em soro fisiológico. A seguir, realizou-se uma leitura inicial, considerada a emissão de luz basal. O hidroperóxido de tertbutila, na concentração de $400 \mathrm{mM}$, foi adicionado ao meio de reação $(30 \mu \mathrm{L})$, para uma concentração final de
3 mM. Foi, então, medida a emissão de luz e, desta, descontada a emissão basal para cálculos. Os resultados foram expressos em contagens por segundo (cps) por miligrama de hemoglobina..$^{8,9}$

\section{Capacidade AntIOXIDANTE TOTAL (TRAP)}

Para mensuração da capacidade antioxidante total Total Reactive Antioxidant Potential (TRAP) ${ }^{10,11}$-, foi utilizada uma técnica baseada na formação de um radical que emite luz, e detectado por contador beta (LKB Rack Beta Liquid Scintilation Spectrometer 1215; LKB Produkter AB, Bromma, Sweden) com o circuito de coincidência desconectado e utilizando o canal de trítio. As medidas foram realizadas em sala escura e em frascos de vidro mantidos na penumbra para evitar a fosforescência ativada pela luz fluorescente. O meio de reação consistiu em $3,0 \mathrm{~mL}$ de uma solução de $\mathrm{AZO}$, à qual se adicionou a quantidade de $10 \mu \mathrm{L}$ de luminol, realizando-se uma leitura basal. Em seguida, adicionou-se a amostra (em torno de $10 \mu \mathrm{L}$ ). Para estabelecer a curva padrão, foram realizadas duas leituras contendo Trolox (vitamina E hidrossolúvel), nas quantidades $5 \mu \mathrm{L}$ e $10 \mu \mathrm{L}$. A primeira leitura foi realizada com ABAP e luminol; nesta, foi verificada a formação de radicais livres, realizando-se, posteriormente, uma curva padrão com a utilização do Trolox como antioxidante, e foi medida a capacidade antioxidante das amostras observando-se o tempo que a amostra inibe a formação dos radicais do luminol. Os resultados foram expressos em $\mathrm{mM}$ de trolox..$^{10,11,12}$

\section{ENZIMAS ANTIOXIDANTES}

A técnica utilizada para determinação da SOD baseiase na inibição da reação do radical superóxido com o pirogalol. O radical superóxido é gerado pela autooxidação do pirogalol quando em meio básico. A SOD presente na amostra compete pelo radical superóxido com o sistema de detecção. A oxidação do pirogalol leva à formação de um produto colorido, detectado espectrofotometricamente a um comprimento de onda de $420 \mathrm{~nm}$. A atividade da SOD foi determinada medindo-se a velocidade de formação do pirogalol oxidado. ${ }^{13}$ Os resultados foram expressos em U SOD/ mg proteína. A atividade da enzima antioxidante catalase (CAT) foi determinada pela medida da redução da absorbância em 240-nm na presença de peróxido de hidrogênio $\left(\mathrm{H}_{2} \mathrm{O}_{2}\right)$. A atividade é expressa em nanomols de $\mathrm{H}_{2} \mathrm{O}_{2}$, reduzidos por minuto por miligrama de proteína. ${ }^{14} \mathrm{~A}$ concentração de proteínas, utilizada 
nos cálculos da atividade das enzimas antioxidantes, foi mensurada pelo método de Lowry et al., usando albumina sérica bovina como padrão. ${ }^{15}$

\section{DETERMINAÇÃO DE NITRATOS E NITRITOS}

Os níveis de nitrato foram estimados pela reação de Griess de acordo com o procedimento descrito por Granger et al. (1999). ${ }^{16}$ As amostras de plasma $(50 \mu \mathrm{L})$ foram incubadas com co-fatores enzimáticos e nitrato redutase, para que o nitrato pudesse ser reduzido a nitrito. Reagente de Griess (1 g sulfanilamide, $0,1 \mathrm{~g}$ naphthylene e $2,3 \mathrm{~mL}$ de ácido fosfórico $85 \%$ ) era adicionado. A absorbância era lida a $540 \mathrm{~nm}$. Os resultados foram avaliados comparando-se com uma curva padrão feita com a utilização de nitrato de sódio $1 \mathrm{mM}$ e os resultados foram expressos como $\mu \mathrm{M}$ de nitrato. ${ }^{16}$

\section{OXIDAÇÃO DE PROTEÍNAS - MÉTODO DAS CARBONILAS}

As amostras de plasma foram incubadas com 2,4 dinitrophenylhydrazine (DNPH $10 \mathrm{mmol} / \mathrm{L}$ ) em solução de $\mathrm{HCl}$ 2,5 mol/L por uma hora em temperatura ambiente. As amostras foram agitadas a cada 15 minutos. A seguir, solução de TCA $20 \%$ foi adicionada aos tubos das amostras, ficando estas reservadas em gelo por 10 minutos e centrifugadas por cinco minutos. Então, as proteínas precipitadas foram coletadas. $\mathrm{O}$ mesmo procedimento foi realizado utilizando-se solução de TCA $10 \%$. O pellet foi lavado por três vezes com etanol: acetato de etila $(1: 1)$ $(\mathrm{v} / \mathrm{v})$. Ao final, o precipitado foi dissolvido em $6 \mathrm{~mol} / \mathrm{L}$ de solução de guanidina, agitando-se as amostras por dez minutos em banho a $37^{\circ} \mathrm{C}$ e lido a $360 \mathrm{nM}$. Os resultados foram expressos em nmol/mg prot. ${ }^{17}$

\section{Análise Estatística}

Depois de efetuados todos os testes, foram calculados as médias e os erros padrões da média para cada uma das medidas realizadas e para cada um dos grupos estudados. Para análise estatística dos dados pré e pós-HD, pré-HD e controle, utilizou-se o teste $t$ de Student, sendo consideradas significativas diferenças com $\mathrm{p}<0,05$.

\section{Resultados}

Neste estudo, foram avaliados o sistema antioxidante de defesa enzimático, por meio da mensuração da atividade das enzimas superóxido dismutase e catalase, e o sistema antioxidante não enzimático, através da avaliação da capacidade antioxidante total. $\mathrm{O}$ dano causado pelo estresse oxidativo foi avaliado por marcadores de dano a lipídios e proteínas, e avaliou-se indiretamente o óxido nítrico através de seus metabólitos, nitritos e nitratos.

$\mathrm{Na}$ Tabela 1, estão expressos os dados dos doentes renais crônicos obtidos antes e após uma sessão de HD. Pode-se observar que não houve variação significativa das enzimas SOD e Catalase após sessão de hemodiálise. Também não foi observada alteração nos níveis de dano oxidativo a lipídios e proteínas, bem como nos níveis de nitratos e nitritos após a HD. No entanto, na Tabela 2, onde os dados dos pacientes em hemodiálise são comparados com os controles, observa-se redução significativa na atividade das enzimas antioxidantes SOD e Catalase nos pacientes renais crônicos. Além de as atividades das enzimas antioxidantes estarem significativamente inferiores

\begin{tabular}{|c|c|c|c|}
\hline Tabela 1 & \multicolumn{3}{|c|}{$\begin{array}{l}\text { NíveIS DE ESTRESSE OXIDATIVO DE PACIENTES RENAIS CRÔNICOS ANTES (PRÉ-HD) } \\
\text { E APÓS (PóS-HD) UMA SESSÃO DE HEMODIÁLISE (HD) }\end{array}$} \\
\hline \multicolumn{2}{|l|}{ Variável } & Pré-HD & Pós-HD \\
\hline \multicolumn{2}{|c|}{ Carbonilas (nmol/mg prot) } & $5,62 \pm 0,46$ & $5,93 \pm 0,52$ \\
\hline \multicolumn{2}{|c|}{ Lipoperoxidação - QL (cps/mg Hb) } & $22.194 \pm 1.734$ & $20.080 \pm 1.624$ \\
\hline \multicolumn{2}{|c|}{ Catalase (pmoles/mg prot) } & $5,08 \pm 0,19$ & $5,03 \pm 0,13$ \\
\hline \multicolumn{2}{|c|}{ Superóxido Dismutase (U/mg prot) } & $3,1 \pm 0,26$ & $3,9 \pm 0,65$ \\
\hline \multicolumn{2}{|c|}{$\begin{array}{l}\text { Capacidade Antioxidante Total } \\
\text { (U Trolox/ } \mu \mathrm{L} \text { de amostra) }\end{array}$} & $1.476 \pm 119$ & $648 \pm 87 *$ \\
\hline \multicolumn{2}{|c|}{ Nitrato $(\mu \mathrm{M})$} & $3,35 \pm 0,41$ & $3,67 \pm 0,33$ \\
\hline \multicolumn{2}{|l|}{ Nitrito $(\mu \mathrm{M})$} & $0,10 \pm 0,01$ & $0,13 \pm 0,01$ \\
\hline
\end{tabular}

Valores expressos em média \pm erro padrão. Diferença significativa $\left({ }^{*}\right)$ entre Pré e Pós- HD pelo teste $t(\mathrm{p}<0,05)$. ( $Q L$ - Quimiluminescência). 


\begin{tabular}{|lll|}
\hline Tabela 2 & $\begin{array}{l}\text { COMPARAÇÃO ENTRE OS NÍVEIS DE ESTRESSE OXIDATIVO DE PACIENTES RENAIS CRÔNICOS ANTES DE UMA } \\
\text { SESSÃO DE HEMODIÁLISE (HD) (PRÉ-HD) E INDIVÍDUOS SAUDÁVEIS (CONTROLE) }\end{array}$ \\
\hline Variável & Pré-HD & Controle \\
\hline Carbonilas (nmol/mg prot) & $5,62 \pm 0,46$ & $3,44 \pm 0,22 *$ \\
\hline Lipoperoxidação - OL (cps/mg Hb) & $22194 \pm 1734$ & $12891 \pm 398 *$ \\
\hline Catalase (pmoles/mg prot) & $5,08 \pm 0,19$ & $7,94 \pm 0,26 *$ \\
\hline Superóxido Dismutase (U/mg prot) & $3,1 \pm 0,26$ & $6,92 \pm 0,18^{*}$ \\
\hline $\begin{array}{l}\text { Capacidade Antioxidante Total } \\
\text { (UTrolox/ } \mu \mathrm{L} \text { de amostra) }\end{array}$ & $1476 \pm 119$ & $279 \pm 28 *$ \\
\hline Nitrato $(\mu \mathrm{M})$ & & $4,35 \pm 0,36$ \\
\hline Nitrito $(\mu \mathrm{M})$ & $3,35 \pm 0,41$ & $0,05 \pm 0,01 *$ \\
\hline
\end{tabular}

Valores expressos em média \pm erro padrão. Diferença significativa $\left(^{*}\right)$ entre Pré e Pós-HD pelo teste $t(p<0,05)$. ( $Q L$ - Quimiluminescência).

na população de renais crônicos, observou-se que o dano oxidativo a lipídios, avaliado pela LPO por quimiluminescência, e o dano a proteínas, avaliado pelos níveis de Carbonilas, estavam significativamente aumentados nesse grupo de pacientes. A atividade antioxidante total apresentou redução significativa após sessão de HD, observada também nos níveis de ácido úrico pré-HD $(6,15 \pm 0,23 \mathrm{mg} / \mathrm{dL})$ e pós-HD $(4,49 \pm$ $0,20 \mathrm{mg} / \mathrm{dL})(\mathrm{p}<0,05)$.

\section{Dıscussão}

A enzima SOD citosólica é cobre e zinco dependente. A diminuição desses íons em pacientes recebendo tratamento hemodialítico pode contribuir para a diminuição da atividade da SOD, ${ }^{1}$ que também pode ser diretamente diminuída por um aumento na produção de íons superóxido e peróxido de hidrogênio. ${ }^{18}$ Além disso, a maioria dos pacientes renais crônicos em HD recebe terapia com eritropoetina e ferro, e sabe-se que o ferro atua como catalisador na geração de espécies ativas de oxigênio, como o tóxico radical hidroxil, e que espécies férricas podem estar envolvidas em diferentes etapas da LPO como iniciação e propagação. ${ }^{6}$ Todos esses fatores podem ter influenciado a atividade da SOD nestes pacientes com consequente diminuição de sua atividade.

A catalase, a exemplo da SOD, não apresentou variação em sua atividade após sessão de hemodiálise. Porém, quando comparadas com o grupo controle, ambas estavam significativamente mais baixas. A exposição a alguns elementos como alumínio, silicone ou ferro durante a diálise, deficiência de algum elemento essencial participante da ativação de algumas enzimas como selênio ou zinco, além de outros fatores ainda não esclarecidos, podem contribuir para a baixa atividade da catalase e SOD nos eritrócitos dos pacientes em tratamento dialítico. ${ }^{19}$

A avaliação da capacidade antioxidante total (TRAP) pode fornecer informações a respeito da capacidade dos sistemas em resistir aos desequilíbrios do estresse oxidativo. ${ }^{12} \mathrm{O}$ método utilizado neste estudo permite medir a capacidade da amostra em agir como antioxidante frente a radicais livres formados. A capacidade apresentada pela amostra é comparada a um padrão, neste caso o Trolox (vitamina $\mathrm{E}$ hidrossolúvel). ${ }^{10,11,12}$ Dentre as substâncias antioxidantes medidas pela técnica, estão: a vitamina $\mathrm{C}$, o ácido úrico e a glutationa, principais antioxidantes não enzimáticos hidrossolúveis do plasma. As substâncias são mensuradas em conjunto e não individualmente.

Níveis de vitamina $\mathrm{C}$ nos pacientes renais crônicos em HD estão, na maioria das vezes, mais baixos que os encontrados em pessoas saudáveis. Além disso, observa-se diminuição nos níveis de vitamina $\mathrm{C}$ ao final da diálise. ${ }^{19}$ Como resultado da ação dos radicais livres, a vitamina E é convertida a $\alpha$-tocoferil, um radical livre. $\mathrm{O}$ radical livre $\alpha$-tocoferil não tem propriedades antioxidantes e pode disparar o processo de peroxidação lipídica das membranas. A vitamina C, um dos antioxidantes medidos pelo TRAP, é uma substância responsável pela regeneração do radical $\alpha$-tocoferil a tocoferol (vitamina E). Essa pode ser uma explicação para a relatada redução concomitante do TRAP e da vitamina $\mathrm{C}$ após sessão de HD.

Clermont et al..$^{21}$ observaram uma depleção acentuada de antioxidantes após sessão de hemodiálise. Os autores encontraram também uma diminuição nos níveis de vitamina $\mathrm{C}$ e tióis, e um aumento nos níveis do radical ascorbil em relação ao nível de vitamina C. A atividade antioxidante do plasma e os níveis de ácido úrico eram significativamente mais altos nos 
pacientes renais crônicos. Após HD, os níveis de vitamina $\mathrm{C}$ diminuíram e a razão radical ascorbil/vitamina $\mathrm{C}$ aumentou, enquanto a capacidade antioxidante do plasma e o nível de ácido úrico eram significativamente mais baixos após o procedimento de diálise. A acentuação nos níveis do radical ascorbil após a diálise demonstra aumento na concentração de espécies ativas de oxigênio. ${ }^{21}$

Erdogan et al.,22 em uma avaliação da capacidade antioxidante total no plasma humano, mostraram que esta era formada pela presença de: urato $(35-65 \%)$, ascorbato $(0-24 \%)$, vitamina $\mathrm{E}(5-10 \%)$ e proteínas $(10-50 \%)$. Neste trabalho, observou-se diminuição paralela em ambos, ácido úrico e estado antioxidante do plasma após sessão de HD, bem como maior TRAP nos pacientes quando comparados aos controles. Esse maior TRAP tem sido atribuído a um aumento no nível de urato desses pacientes, e os resultados deste trabalho estão em consonância com achados da literatura. ${ }^{21}$

A depleção da capacidade antioxidante é atribuída em grande parte à eliminação do ácido úrico pela diálise. Em adição, é frequente a perda de antioxidantes causada pela remoção de antioxidantes solúveis em água durante sessão de hemodiálise devido ao seu baixo peso molecular. As defesas também podem ser enfraquecidas pela perda causada em função de grande produção de radicais livres. ${ }^{23}$

A alta capacidade antioxidante não indica melhora das defesas antioxidantes e não exclui a deficiência de alguns antioxidantes..$^{20}$ Nas amostras de soro e saliva, valores de TRAP são enfaticamente correlacionados com o ácido úrico devido à alta concentração desse antioxidante. Essa dependência dos valores de TRAP com a concentração de um antioxidante em que a concentração é pouco relacionada com o estresse oxidativo limita a utilização dessa técnica como um índice de estado antioxidante no plasma. ${ }^{12}$ Medidas diretas dos níveis de vitaminas e outros antioxidantes hidrossolúveis poderiam auxiliar na discussão desses dados.

Vários estudos mostram que marcadores de estresse oxidativo estão aumentados na insuficiência renal crônica. ${ }^{7,24,25} \mathrm{Um}$ dos marcadores avaliado neste estudo foi a determinação do dano oxidativo aos lipídios, lipoperoxidação (LPO). A LPO tem-se mostrado envolvida na patogênese de doenças como aterosclerose e câncer, doenças comumente encontradas entre os pacientes renais crônicos que realizam HD.

Os radicais livres atacam os ácidos graxos poliinsaturados das membranas celulares, resultando na formação de produtos da LPO como dienos conjugados e malondialdeído (MDA), um dos componentes medidos pelo TBARS, que é um método bastante difundido, porém, pouco sensível e específico. Sabe-se que muitos fatores, como composição dos ácidos graxos, quantidade de gordura e de antioxidantes, podem modificar essa reação. ${ }^{26}$ Durante HD, ocorre influência de diversas substâncias incluindo glicose, que podem afetar a reação com o TBA. Desse modo, é necessária a utilização de uma técnica mais sensível para melhorar a qualidade e a acurácia nas determinações de lipoperoxidação na doença renal crônica. ${ }^{5,3}$ A determinação da LPO neste trabalho foi feita pela técnica de quimiluminescência (QL), descrita por Gonzalez-Flecha et al. ${ }^{9}$ Essa técnica tem sido usada para determinar a ocorrência de estresse oxidativo em diversas situações patológicas e é um método bastante sensível para medida da LPO. Analisando os dados apresentados nas Tabelas 1 e 2, observa-se que os valores da QL não foram modificados pela sessão de HD e que eram significativamente maiores que o grupo controle. Embora a técnica adotada para a mensuração do dano aos lipídios seja diferente da utilizada habitualmente, os resultados apontam para um mesmo caminho, um importante estado de estresse oxidativo nestes pacientes, não sendo alterado por uma única sessão de hemodiálise.

Acredita-se que um caminho compartilhado por ambos, hemodiálise e uremia, uma vez que o aumento do estresse oxidativo tem sido descrito em todos os estágios da doença renal, é a amplificação das respostas inflamatórias. Um estímulo disparador inicial poderia provocar a produção de citoquinas inflamatórias ou aumento das EAO, como o superóxido e o peróxido de hidrogênio. Além disso, a falta de defesas antioxidantes para encerrar ou diminuir essa resposta amplificada poderia levar a um crônico ciclo vicioso de radicais livres causando produção de mediadores inflamatórios que voltam a estimular a produção desses radicais livres. Essa produção crônica pode lesar proteínas, lipídios de membrana e DNA, mantendo altos os índices de estresse oxidativo nesses pacientes. ${ }^{23}$

Tem-se estabelecido que as proteínas representam alvos para a injúria mediada por oxidantes. $\mathrm{O}$ ataque de espécies ativas de oxigênio às proteínas pode levar a alterações funcionais e, em particular, à perda progressiva de suas propriedades metabólicas, enzimáticas ou imunológicas. Produtos da oxidação de proteínas e produtos da oxidação de bases de DNA ${ }^{27,28,29,30,31}$ também têm sido sugeridos como importantes índices de estresse oxidativo. Essa nova linha de estudo indica que a mensuração de proteínas oxidadas pode apresentar algumas vantagens na comparação com produtos da lipoperoxidação por sua formação ser relativamente precoce e pela relativa estabilidade desses compostos. ${ }^{22}$ 
A formação de carbonilas representa um marcador precoce da oxidação de proteínas. Elas envolvem cátions do ciclo redox como o ferro e cobre, os quais têm locais de ligação em proteínas e podem transformar resíduos de aminoácidos em carbonilas na presença de peróxido de hidrogênio e ânion superóxido. Os aminoácidos lisina, arginina, prolina e histidina são os mais propensos em gerar carbonilas. ${ }^{29,30}$

No presente trabalho, avaliou-se oxidação de proteínas no plasma pela técnica das carbonilas. ${ }^{17}$ Os dados apresentados mostram os níveis de carbonilas no plasma de pacientes renais crônicos em HD, significativamente elevados quando comparados com indivíduos controle. Esse alto índice de dano às proteínas, observado nos pacientes renais crônicos, não foi modificado após uma única sessão de hemodiálise.

Além da avaliação de espécies ativas de oxigênio, foram efetuadas medidas relativas aos metabólitos do $\mathrm{NO}$, uma espécie ativa de nitrogênio. O NO, também conhecido como fator de relaxamento dependente do endotélio, é um gás hidrofóbico responsável por controlar o tônus vascular, promovendo vasodilatação, por inibir alguns processos como agregação plaquetária, adesão de leucócitos ao endotélio, produção de endotelinas (peptídeos com potente ação vasocontritora). ${ }^{32}$ Causa também variação na força de contração e frequência cardíaca. O NO é liberado quando ocorre aumento no fluxo sanguíneo, aumento do estresse de cisalhamento (shear stress) e aumento da pressão arterial, provocando relaxamento dos vasos. Esse é um mecanismo de adaptação que contribui para manter a pressão arterial em valores normais. Um aumento na produção de EAO, como superóxido, peróxido de hidrogênio e lipoperóxidos, além de diminuição da síntese de NO, foi observado em pacientes com hipertensão essencial, quando comparados a indivíduos normais. Esses indivíduos com hipertensão arterial ainda apresentam diminuídas concentrações de antioxidantes tais como a vitamina $\mathrm{E}$ e SOD. ${ }^{32}$

Em hipertensão por doença renal crônica, observou-se inibição na síntese de NO. ${ }^{33}$ Porém, quando esses pacientes são submetidos a sessões de HD, um aumento de NO pode estar sendo induzido pelo aumento do fluxo sanguíneo e estresse de cisalhamento a que o sangue é submetido durante o procedimento. Esse aumento de NO, juntamente com a perda de volume, parece ser um dos fatores responsáveis pela hipotensão apresentada por alguns pacientes durante HD. O superóxido circulante pode reagir com o $\mathrm{NO}$, inativando-o e formando nitratos, ou peroxinitrito (ONOO-), que é um produto tóxico altamente oxidante. A diminuição espontânea do peroxinitrito pode levar à formação de nitrito e radical hidroxil. ${ }^{34}$ Esse mecanismo pode explicar o aumento significativo nos níveis de nitrito observados nos pacientes renais após sessão de hemodiálise. Apesar de um metabólito do NO estar aumentado após $\mathrm{HD}$, não se observou aumento nos níveis de LPO e de carbonilas após o procedimento. Isso poderia estar sendo combatido pelo sistema antioxidante não enzimático, que teve redução importante durante o procedimento de HD. Outra hipótese é que uma única sessão de HD, em função do pequeno espaço de tempo, não seria suficiente para detectar o dano causado por esses radicais, já que, quando há aumento nos níveis de nitritos, também existe aumento do radical hidroxil.

Um conjunto de fatores, como aumento de espécies ativas de oxigênio, redução na atividade de enzimas antioxidantes e redução na concentração de antioxidantes não enzimáticos após a HD, pode constituir um ciclo vicioso de estresse oxidativo nesses pacientes.

\section{Conclusão}

A partir dos resultados obtidos, pode-se concluir que o estresse oxidativo avaliado em pacientes renais crônicos que realizam HD é significativamente maior que o observado em indivíduos saudáveis, evidenciado pelo aumento significativo nos níveis de lipoperoxidação e oxidação de proteínas, redução significativa da atividade das enzimas antioxidantes SOD e CAT e por níveis aumentados de nitritos. Uma única sessão de HD não modificou os níveis de estresse oxidativo sistêmico apresentados por estes pacientes.

\section{RefERÊNCIAS}

1- Paul JL, Sall ND, Soni T et al. Lipid peroxidation abnormalities in hemodialyzed patients. Nephron 1993; 64:106-9.

2- Nguyen-khoa T, Massy ZA, Bandt JP et al. Oxidative stress and haemodialysis: role of inflammation and duration of dialysis treatment. Nephrol Dial Transplant 2001; 16:335-40.

3- Schettler V, Wieland E, Verwiebe R, Schuffwerner P, Scheler F, Oellerich M. Plasma lipids are not oxidized during hemodialysis. Nephron 1994; 67:42-7.

4- Boaz M, Matas Z, Biro A et al. Serum malondialdehyde and prevalent cardiovascular disease in hemodialysis. Kidney Int 1999; 56:1078-83.

5- Hirayama A, Nagase S, Gotoh $M$ et al. Hemodialysis does not influence the peroxidative state already present in uremia. Nephron 2000; 86:436-40.

6- Crisol JP, Bosc JY, Badiou S et al. Erythropoietin and oxidative stress in haemodialysis: beneficial effects of vitamin E supplementation. Nephrol. Dial Transplant 1997; 12:2312-7. 
7- Zwolinska D, Grzeszczak W, Szxzepanska M, Killis-Pstrusinska K, Szprynger K. Lipid peroxidation and antioxidant enzymes in children on maintenance dialysis. Ped Nephrol 2006; 21:705-10.

8- Llesuy SF, Milei J, Flecha BSG, Boveris A. Myocardial damage induced by doxorubicins: hydroperoxide-initiated chemiluminescence and morphology. Free Rad Biol Med 1990; 8:25964.

9- Gonzalez Flecha B, Llesuy S, Boveris A. Hydroperoxide-initiated chemiluminescence: an assay for oxidative stress in biopsies of liver, heart and muscle. Free Rad Biol Med 1991; 10:41-7.

10- Lissi E, Pascual C, Del Castillo MD. Luminol luminescence induced by 2,2'- azobis (2-amidinopropane) thermolysis. Free Rad Res Comms 1992; 17:299-311.

11- Lissi E, Salim-Hanna M, Pascual C, Castillo MD. Evaluation of total antioxidant reactivity from luminol-enhaced chemiluminescence measurements. Free Rad Biol Med 1995; 18:153-8.

12- Evelson P, Travacio M, Repetto M, Escobar J, Llesuy S, Lissi EA. Evaluation of total reactive antioxidant potential (TRAP) of tissue homogenates and their cytosols. Arch Biochem Biophys 2001; 388:261-6.

13- Marklund S. Handbook of methods for oxygen radical research. Boca Raton: CRC Press, 1985, pp. 243-7.

14-Aebi Catalase in vitro. Meth Enzymol 1984; 105:121-6.

15 - Lowry OH, Rosebrough NJ, Farr AL, Randahll RJ. Protein measurement with the folin phenol reagent. J Biol Chem 1951; 193:265-75.

16-Granger DL, Anstey NM, Miller WC, Weinberg JB. Measuring nitric oxide production in human clinical studies. Meth Enzymol 1999; 301:58-61.

17- Reznick AZ, Packer L. Carbonyl assays for determination of oxidatively modified proteins. Meth Enzymol 1994; 233:357-63.

18-Travacio M, Llesuy S. Antioxidant enzymes and their modification under oxidative stress conditions. J Br Assoc Adv Sci 1996; 48:9-13.

19-Durak I, Akyol Ö, Basesme E, Canbolat O, Kavutçu M. Reduced erythrocyte defense against free radical toxicity in patients with chronic renal failure. Nephron 1994; 66:76-80.

20 - Eiselt J, Racek J, Trefil L, Opatrný Jr.K. Effects of a vitamin E-modified dialysis membrane and vitamin $\mathrm{C}$ infusion on oxidative stress in hemodialysis patients. Artificial Organs 2001; 25:430-6.

21-Clermont G, Lecour S, Lahet JJ et al. Alteration in plasma antioxidant capacities in chronic renal failure and hemodialysis patients: a possible explanation for the increased cardiovascular risk in these patients. Cardiovasc Res 2000; 47:618-23.
22- Erdogan C, Ünlüçerçi Y, Türkmen A, Kuru A, Çetin Ö, Bekpmar S. The evaluation of oxidative stress in patients with chronic renal failure. Clinica Chimica Acta 2002; 322:157-61.

23- Wratten ML, Tetta C, Ursini F, Sevanian A. Oxidant stress in hemodialysis: prevention and treatment strategies. Kidney Int 2000; 58:12632.

24- Bayes B, Pastor MC, Bonal J, Foraster A, Romero R. Oxidative stress, inflammation and cardiovascular mortality in haemodialysis-role of seniority and intravenous ferrotherapy: Analysis at 4 years of follow-up. Nephrol Dial Transplant 2006; 21:984-90.

25- Valko M, Leibfritz D, Moncol J, Cronin MTD, Mansur M, Telser J. Free radicals and antioxidants in normal physiological functions and human disease. Int J Biochem Cell Biol 2007; 39:4484.

26-Janero DR. Malondialdehyde end thiobarbituric acid-reactivity as diagnostic indices of lipid peroxidation and peroxidative tissue injury. Free Rad Biol Med 1990; 9:515-40.

27-Davies KJ. Protein damage and degradation by oxygen radicals: general aspects. J Biol Chem 1987; 262:9895-901.

28-Witko-Sarsat V, Descamps-Latscha B. Advanced oxidation proteins products: novel uraemic toxins and pro-inflammatory mediators in chronic renal failure? Nephrol Dial Transplant 1997; 12:1310-2.

29-Descamps-Latscha B, Witko-Sarsat V. Importance of oxidatively modified proteins in chronic renal failure. Kidney Int 2001; 59:108-13.

30-Descamps-Lastscha B, Drüeke T, Witko-Sarsat V. Dialysis induced oxidative stress: biological aspects, clinical consequences, and therapy. Semin Dial 2001; 14:193-9.

31-Tarng DC, Huang TP, Liu TY, Chen HW, Sung YJ, Wei YH. Effect of vitamin E-bonded membrane on the 8-hydroxy 2'-deosyguanosine level in leukocyte DNA of hemodialysis patients. Kidney Int 2000; 58:790-9.

32-Kumar KV, Das UN. Are free radicals involved in the pathobiology of human essencial hypertension? Free Rad Res Comms 1993; 19:59-66.

33- Kuo PC, Schroeder RA. The emerging multifaceted roles of nitric oxide. Annals of Surgery 1995; 221:220-35.

34-Denicola A, Souza JM, Gatti RM, Augusto O, Radi R. Desferrioxamine inhibition of the hydroxyl radical-like reactivity of peroxynitrite: role of the hydroxamic groups. Free Rad Biol Med 1995; 19:11-9. 